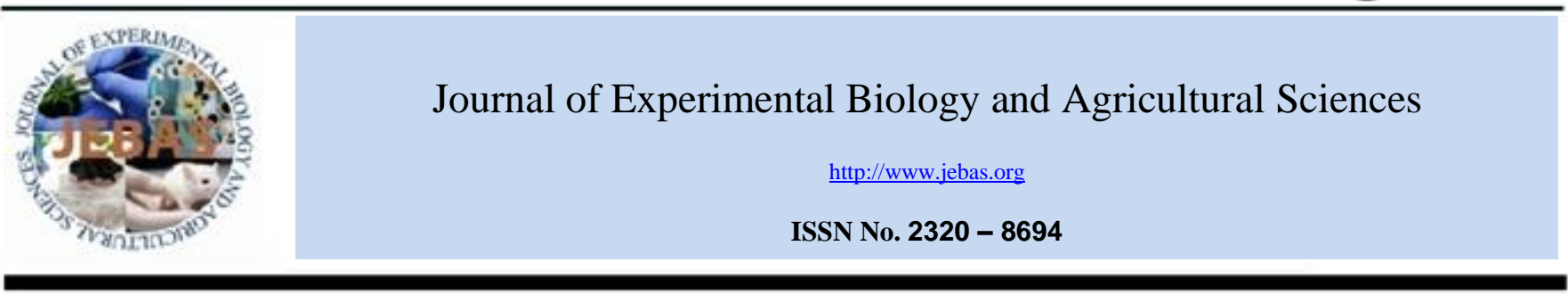

\title{
EFFECT OF UNILATERAL CRYPTORCHIDISM ON MOBILITY AND VELOCITY PARAMETERS OF SPERM IN (Bos frontalis) SEMEN
}

\author{
Perumal $\mathrm{P}^{1, *}$, Chang $\mathrm{S}^{1}$, Sangma $\mathrm{CTR}^{1}$, Khate $\mathrm{K}^{1}$ and Saminathan $\mathrm{M}^{2}$ \\ ${ }^{1}$ ICAR-National Research Centre on Mithun, Jharnapani, Nagaland - 797106 (India) \\ ${ }^{2}$ ICAR-Indian Veterinary Research Institute, Izatnagar, Bareilly, Uttar Pradesh- 243122 (India)
}

Received - August 03, 2016; Revision - October 15, 2016; Accepted - October 30, 2016

Available Online - October 30, 2016

DOI: http://dx.doi.org/10.18006/2016.4(Spl-3-ADPCIAD).S116.S122

\begin{abstract}
KEYWORDS
Mithun

Cryptorchid

Computer assisted sperm

analysis

Motility

Velocity parameters

ABSTRACT

The present study was conducted to assess the motility and velocity parameters of sperm of normal intact and unilateral cryptorchid mithun bull by computer assisted sperm analyzer (CASA). Twenty ejaculates were collected from cryptorchid $(n=10)$ and normal intact $(n=10)$ bull. The different parameters assessed through CASA were static sperms (SM), Total Motility (TM), forward progressive motility (FPM), Average Path velocity (VAP), Average beat/cross frequency (BCF), Straightness (STR), Average straight line velocity (VSL), Average curvilinear velocity (VCL), Average amplitude of lateral head displacement (ALH), Wobble (WOB), Linearity (LIN), Elongation (EL). The result showed that these CASA parameters differed significantly $(p<0.05)$ between the intact and cryptorchid mithun bull and intact mithun bull has significantly $(\mathrm{p}<0.05)$ higher value than cryptorchid mithun bulls. It was concluded that most of the CASA parameters were significantly lower in cryptorchid bulls than intact bull and however, due to the genetic hereditary nature of cryptorchid, these bulls should not be used for breeding purposes.
\end{abstract}

\section{* Corresponding author \\ E-mail: perumalponraj@gmail.com (Perumal P)}

Peer review under responsibility of Journal of Experimental Biology and Agricultural Sciences.

Production and Hosting by Horizon Publisher India [HPI] (http://www.horizonpublisherindia.in/).

All rights reserved.
All the article published by Journal of Experimental Biology and Agricultural Sciences is licensed under a Creative Commons Attribution-NonCommercial 4.0 International License Based on a work at www.jebas.org.

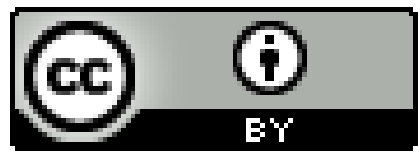




\section{Introduction}

Cryptorchidism is referred to an abnormal retention of undescended testicle, which may be retained within the abdominal cavity or inguinal canal. Generally, cryptorchidism is detected at time of birth or thereafter shortly. Cryptorchidism may be unilateral or bilateral and unilateral cryptorchidism is more common in all the species. Incidence of cryptorchidism in bovine species is very low as compared to other domestic animals species (about $0.1 \%$ ) and this defect is hereditary in nature. Among the cryptorchidism, incidence of unilateral was represented as 78, 90, 45-70, 81-93, 66-89, 59, 100 and $62 \%$, respectively for different species such as feline, bovine, canine, equine, humans, porcine, rabbits and ovine, respectively (Amann \& Veeramachaneni, 2007). Location of undescended /retention testis also varied depending upon species of the animals (Amann \& Veeramachaneni, 2007). In general, cryptorchid testes are hypoplastic and atrophied and do not produce spermatozoa/ aspermatogenesis and bilateral cryptorchids are sterile in nature (Kawakami et al., 1995). But unilateral cryptorchids may be fertile if the descended contralateral testis is functional (Kaki \& Sofikitis, 1999). Percentage of infertility in unilateral cryptorchidism differed between 10 (Tellaloglus et al., 1994) to $100 \%$ (Patkowski et al., 1992), but in bilateral, it is $100 \%$ as both testes are not functional. Studies were done on different species such as bovine for the harmful effects of cryptorchidism on seminal parameters (Marcus et al., 1997), canine (Kawakami et al., 1995), porcine (Pinart et al., 1999), equine (Ras et al., 2010), ovine (Smith et al., 2012), caprine (Igbokwe et al., 2013) and human (Mieusset et al., 1995).

Subjective analysis of semen is carried out by traditional conventional method like assessment of morphology, viability, concentration and motility by bright field phase contrast microscope in frozen semen bank and andrological laboratory (Iguer-Ouada et al., 2001). The evaluation of semen quality parameters such as sperm head behavior, swimming pattern, motility, velocity etc., may benefit in better understanding of the probable and possible function of sperm, semen quality and selection of suitable semen and bulls for ultralow temperature preservation in the mountain animal species. Various models/methods are available to estimate sperm motility and velocity parameters such as time-exposure or multiple exposure photomicrography to the very sophisticated and accurate analyser like computer-assisted sperm analysis (CASA) techniques (Mortimer, 1997). Sophisticated Computerized method of semen analysis supports accurate, reliable, objective assessment, repeatable results in various semen quality parameters, sperm concentration, total and progressive forward motility and various velocity and motility parameters based on the measurement of single and individual sperm cells (Verstegen et al., 2002).

Similarly, recent finding supported that CASA system not only estimate the proportion of motile spermatozoa but also assess other sperm motion and velocity parameters derived from individual spermatozoa. Further, it has higher predictive power on sperm fertility potential of sperm and semen (Mortimer, 1994). In addition to the use of sophisticated computerized techniques to prognoses the semen fertility, CASA also provides a useful tool to study the effects of different in vitro and in vivo protocols on sperm velocity and motility as well as the means to study the phenomenon of sperm hyper-activation. Bull fertility was positively correlated with several spermatozoa functional kinematic parametric indexes such as TM, LIN, VSL, PFM, ALH and VCL (Farrell et al., 1996; Perumal et al., 2011). Perusal of literatures showed no reports on velocity and motility parameters in semen mithun suffered cryptorchidism. Hence, the objective of this study was to assess the effect of unilateral cryptorchidism on motility and velocity parameters of mithun semen with computer assisted sperm analyser to pursuit future sperm preservation protocols.

\section{Materials and Methods}

A mono-cryptorchid and a normal apparently healthy bull of same age with good body condition (score 5-6) maintained under uniform housing, feeding, lighting and managemental conditions at the NRC on Mithun, Nagaland, India were selected for the present study. Assessment and confirmation by several examinations and evaluation like palpation of testes, per rectal examination and visual for cryptorchidism condition were carried out. The semen ejaculates were collected from the mithuns affected and unaffected through transrectal manual massage method two times in a week (Palmer et al., 2004). The necessary experimental protocols performed was whereby carried out as per the regulations implemented by the Institutional Animal Care and Use Committee.

Using the Hamilton Thorne Sperm Analyzer the motility and velocity parameters of sperm were assessed (HTM-IVOS, Version 10.8, MA, USA). The sophisticated computer system contains of a computer analyzing and saving the data, phasecontrast microscope, mini-therm heating stage, camera and image digitizer. The software settings were prepared as follows. Chamber type: Leja 4, fields acquired: 10, temperature of analysis $\left({ }^{\circ} \mathrm{C}\right): 37.0$, frame rate $(\mathrm{Hz}): 60$, minimum static contrast: 35 , number of frames: 30 , minimum cell size (pixels): 5, VAP cut - off $(\mu \mathrm{m} / \mathrm{s}): 30$, STR (\%): 70, Prog.min VAP $(\mu \mathrm{m} / \mathrm{s}): 50$, cell intensity: 80 , VSL cut-off $(\mu \mathrm{m} / \mathrm{s})$ : 15and magnification: 1.89 .

Immediately, after semen collection, the sperm concentration was first measured with a phase-contrast microscope (Nikon, Eclipse $80 \mathrm{i}$; $400 \times$ magnification). Semen $(25 \mu \mathrm{L})$ of was diluted with 50-100 $\mu \mathrm{L}$ of Tris (formulated for bull semen) and $5 \mu \mathrm{L}$ of this extended semen was pipetted into a pre-warmed $\left(37^{\circ} \mathrm{C}\right)$ dual chamber disposable Leja slide and was allowed to settle on the mini-therm thermo stage $\left(38^{\circ} \mathrm{C}\right)$ just before the assessment of motility and velocity parameters. 
Table 1 spermatozoa motility and velocity parameters of cryptorchid mithun bull.

\begin{tabular}{|lcc|}
\hline CASA motility and velocity Parameters & $\begin{array}{c}\text { Normal intact mithun bull } \\
\text { semen }(\mathbf{n}=\mathbf{2 5})\end{array}$ & $\begin{array}{c}\text { Unilateral cryptorchid mithun bull } \\
\text { semen }(\mathbf{n = 2 5})\end{array}$ \\
\hline Forward Progressive motility $(\boldsymbol{\%})$ & $86.00 \pm 2.42^{\mathrm{b}}$ & $60.90 \pm 3.19^{\mathrm{a}}$ \\
\hline Total Motility $(\boldsymbol{\%})$ & $40.80 \pm 2.50^{\mathrm{b}}$ & $23.50 \pm 1.89^{\mathrm{a}}$ \\
\hline Curvilinear Velocity $(\mathbf{V C L})(\boldsymbol{\mu m} / \mathbf{s e c})$ & $260.38 \pm 8.43^{\mathrm{b}}$ & $68.89 \pm 5.73^{\mathrm{a}}$ \\
\hline Straight line Velocity $(\mathbf{V S L})(\boldsymbol{\mu m} / \mathbf{s e c})$ & $102.90 \pm 5.34^{\mathrm{b}}$ & $98.74 \pm 3.21^{\mathrm{a}}$ \\
\hline Average path Velocity $(\mathbf{V A P})(\boldsymbol{\mu m} / \mathbf{s e c})$ & $144.31 \pm 6.36^{\mathrm{a}}$ \\
\hline Linearity $(\mathbf{L I N})(\%)$ & $49.30 \pm 1.84^{\mathrm{b}}$ & $36.60 \pm 1.61^{\mathrm{a}}$ \\
\hline Straightness $(\mathbf{S T R})(\boldsymbol{\%})$ & $78.90 \pm 2.04^{\mathrm{b}}$ & $67.00 \pm 1.76^{\mathrm{a}}$ \\
\hline Wobble $(\mathbf{W B})(\%)$ & $55.22 \pm 1.42^{\mathrm{b}}$ & $51.93 \pm 1.58^{\mathrm{a}}$ \\
\hline Amplitude of Lateral Head displacement $(\mathbf{A L H})(\boldsymbol{\mu m})$ & $10.01 \pm 1.39^{\mathrm{b}}$ & $4.90 \pm 1.13^{\mathrm{a}}$ \\
\hline Beat/Cross Frequency $(\mathbf{B C F})(\mathbf{H z})$ & $27.55 \pm 1.84^{\mathrm{b}}$ & $21.35 \pm 1.96^{\mathrm{a}}$ \\
\hline
\end{tabular}

Figures with same superscript $(a, b)$ do not differ significantly $(\mathrm{p}<0.05)$ in rows

Assessment for the following velocity and mobility parameters such as percentage of VCL $(\mu \mathrm{m} / \mathrm{sec})$, BCF $(\mathrm{Hz}), \mathrm{LIN}(\%)$, STR $(\%)$, slowVSL $(\mu \mathrm{m} / \mathrm{sec})$, VAP $(\mu \mathrm{m} / \mathrm{sec})$, ALH $(\mu \mathrm{m})$, WOB $(\%)$, velocities of static, medium \& rapid, FPM and TM were done through CASA. A Minimum of 200 spermatozoa were assessed from at least different two drops of individual sample from each semen ejaculates. The objects were incorrectly observed as spermatozoa were manually deleted and final assessment was done for each semen sample.

The results in the present study were statistically analysed and presented as the mean \pm S.E.M. With the help of student ${ }^{\star} t$ ' test using the SPSS/PC computer program the significant differences between the ejaculates of normal and cryptorchid mithun were estimated (version 15.0; SPSS, Chicago, IL). Values of $\mathrm{p}<0.05$ was found for statistically significant differences. With the help of correlation coefficient the correlation between the motility and velocity parameters were established.

\section{Results and Discussion}

The percent of total motility and forward progressive motility were significantly $(p<0.05)$ higher in ejaculates of normal noncryptorchid than in cryptorchid mithun bulls. Similarly, velocity parameters were significantly $(\mathrm{p}<0.05)$ higher in normal non-cryptorchid than in cryptorchid mithun bulls (Table 1). Thus, it may enhance the quality of semen by cryopreserving effectively in artificial breeding procedure.

There was no report on motility and velocity parameters of CASA on cryptorchid mithun bull semen and to the best of our knowledge this is the first report of the measurement of motility and velocity parameters by the sophisticated sperm analyser. It is subjective and difficult for determining the sperm motility using the traditional conventional simple microscopical models/ methods. Reports have been made, wherein the estimation of velocity motility parameters of the same ejaculates had shown high variations (Mortimer et al. 1986). Computer sperm analysis is an accurate technique utilized for the measurement of the velocity and motility parameters of mithun semen. In a span short time period high numbers of spermatozoa/semen can be estimated individually (Verstegen et al., 2002).

As compared with the report of early authors, the velocity and motility parameters were highly varied in mithun bulls (Farrell et al., 1996). Velocity and motility parameters had shown distinct differences with the parameters like time of collection, energy stores of sperm, age, time between ejaculations, viscosity, $\mathrm{pH}$, ionic concentration, presence of agglutins and detergents, osmolarity, temperature in the seminal plasma and also the availability of the mineral elements like copper, zinc, manganese, and other hormones, PGs, etc. (Blasco, 1984).

The sperm mobility character can be contributed to specific sperm velocity parameters of individual sperm as determined by computer assisted sperm analysis. The velocity and motion parameters like VSL, LIN and BCF are very important for the overall characters of spermatozoa in bulls and as these parameters were significantly associated with sperm mobility and velocity. Experiment carried on for various types of sperm mobility representing VCL, VSL, VAP, LIN, STR, WOB, $\mathrm{ALH}, \mathrm{BCF}$ and others have been shown in Table 1 . The parameters VSL, VAP, VCL, LIN, and BCF were also significantly higher for the ejaculates collected from the normal intact mithun bulls as high mobility as compared with the cryptorchid mithun males. Thus, high-mobility sperm swim faster and straighter than did low-mobility sperm. This is due biologically significant as because the sperm mobility and velocity phenotype on the basis of investigation with the ejaculates is diagnosis of fertility (Froman \& Feltmann, 1998; Froman et al., 1999).

The result of the present study revealed that the percent of total motility and forward progressive motility were significantly higher in intact mithun bulls than cryptorchid mithun bulls. Similarly, velocity parameters were significantly higher in intact mithun bulls than cryptorchid mithun bulls. Similar report was not available in cattle and other species to compare the present study results. 
Table 2 Correlation between the motility and velocity parameters of sperm of normal intact mithun semen.

\begin{tabular}{|c|c|c|c|c|c|c|c|c|c|c|}
\hline & FPM & TM & VCL & VSL & VAP & LIN & STR & WOB & ALH & $\mathrm{BCF}$ \\
\hline FPM & 1.00 & $0.74 *$ & $0.67 *$ & $0.69 *$ & $0.72 *$ & 0.55 & $0.70 *$ & $0.65 *$ & $0.65 *$ & $0.66 *$ \\
\hline $\mathbf{T M}$ & & 1.00 & $0.95 *$ & $0.93 *$ & $0.94 *$ & $0.73 *$ & $0.82 *$ & $0.72 *$ & $0.93 *$ & $0.95 *$ \\
\hline VCL & & & 1.00 & $0.95 *$ & $0.97 *$ & $-0.85 *$ & -0.85 & $0.65 *$ & $0.95 *$ & $0.94 *$ \\
\hline VSL & & & & 1.00 & $0.95 *$ & $-0.76^{*}$ & $-0.80 *$ & $0.66 *$ & $0.94 *$ & $0.93 *$ \\
\hline VAP & & & & & 1.00 & $-0.84 *$ & $-0.88 *$ & $0.78 *$ & $0.97 *$ & $0.94 *$ \\
\hline LIN & & & & & & 1.00 & $0.77 *$ & -0.45 & $-0.76^{*}$ & $-0.75 *$ \\
\hline STR & & & & & & & 1.00 & $-0.93 *$ & $-0.85 *$ & $-0.86 *$ \\
\hline WOB & & & & & & & & 1.00 & $0.74 *$ & $0.76^{*}$ \\
\hline ALH & & & & & & & & & 1.00 & $0.93 *$ \\
\hline BCF & & & & & & & & & & 1.00 \\
\hline
\end{tabular}

*Correlation coefficient were significant, $\mathrm{p}<0.05$

However, the motility and velocity parameters were measured by CASA in domestic animal species such as crossbred cattle (Perumal, 2008; Perumal et al., 2011), Bali cattle (Sarsaifi et al., 2013), buffalo (Anil Kumar et al., 2011; Koonjaenak et al., 2007), sheep (Kumar et al., 2010), goat (Kozdrowski et al., 2007), boar (Broekhuijse et al., 2012) and dog (Domosławska et al., 2013).

The cryptorchid mithun showed the decreased sperm motility \& velocity and all motile spermatozoa were also nonprogressive in nature as reported in other affected domestic livestock animals (Pinart et al., 1999). Most common reason of reduced motility and velocity in cryptorchid bull are abnormal spermatogenesis and spermiogenesis, which alter the ultrastructure of sperm tail (Gopalkrishnan et al., 1995), affects the secretory activity of accessory sex glands and epididymal epithelium, which changes the biochemical structure of epididymal fluid, leads to poor development of sperm motility and velocity in the epididymal duct (Yeung et al., 1993) and vitiated (impaired) functionality of the accessory sex glands may not only produces changes in the ejaculate volume, but even changes in the semen osmolality that are responsible for alterations of motility and velocity of spermatozoa (Gopalkrishnan et al., 1995).

Semen samples with high forward progressive motility and total motility had significantly higher positive correlation with velocity parameters in normal intact mithun bull (Table 2). The ejaculates with high PFM and TM had significantly higher average path velocity, progressive velocity and track speed. This was similar to the findings of earlier reports (Anil Kumar et al., 2011; Perumal et al., 2011; Perumal, 2008) for path velocity. The VAP was highly significant and correlated positively with track speed, progressive velocity and ALH. Similarly, the highly significant positive correlation was observed between VAP, VCL, VSL and ALH, between VCL and VSL and between ALH with VSL, VAP and VCL suggested that the velocity ad motility parameters were correlated, interrelated and associated among the velocity parameters and with amplitude of lateral displacement. Beat cross frequency was significantly and positively highly correlated with ALH. Anil Kumar et al. (2011), Perumal et al. (2011) observed that a positive correlation was similar to the present experiment between beat cross frequency and ALH. $\mathrm{BCF}$ and $\mathrm{ALH}$ indicating the head behaviour of the sperm are significantly variable and average value of these parameters were observed within the range from the previous studies. The authors also found that there was a highly significant negative correlation observed between STR and WOB and a similar result was observed in the present study. In cryptorchid mithun semen, there was positive correlation between the VCL and, VSL, VAP, ALH, BCF. Similarly, in normal intact bull, VCL is positively correlated with VSL, VAP, STR, ALH and BCF and negatively correlated with WOBB (Table 3) (Anil Kumar et al., 2011; Perumal et al., 2011).

Table 3 Correlation between the motility and velocity parameters of sperm of unilateral cryptorchid mithun semen.

\begin{tabular}{|c|c|c|c|c|c|c|c|c|c|c|}
\hline & FPM & TM & VCL & VSL & VAP & LIN & STR & WOB & ALH & BCF \\
\hline FPM & 1.00 & 0.59 & 0.04 & 0.12 & -0.08 & -0.08 & -0.12 & -0.06 & 0.11 & -0.15 \\
\hline TM & & 1.00 & 0.26 & 0.15 & 0.16 & -0.32 & -0.22 & -0.38 & 0.13 & 0.22 \\
\hline VCL & & & 1.00 & $0.86^{*}$ & $0.92 *$ & -0.24 & 0.04 & -0.52 & $0.93 *$ & $0.85 *$ \\
\hline VSL & & & & 1.00 & $0.89 *$ & 0.27 & 0.11 & -0.58 & $0.86 *$ & 0.64 \\
\hline VAP & & & & & 1.00 & -0.12 & 0.13 & -0.33 & $0.97 *$ & $0.81 *$ \\
\hline LIN & & & & & & 1.00 & $0.85 *$ & 0.62 & -0.12 & -0.43 \\
\hline STR & & & & & & & 1.00 & 0.17 & 0.22 & -0.19 \\
\hline WOB & & & & & & & & 1.00 & -0.43 & $0.94 *$ \\
\hline ALH & & & & & & & & & 1.00 & $0.81 *$ \\
\hline BCF & & & & & & & & & & 1.00 \\
\hline
\end{tabular}

*Correlation coefficient were significant, $\mathrm{p}<0.05$ 
Spermatozoa with progressive forward motility along with certain velocity parameters are essential for the spermatozoa to reach the site of fertilization and achieve fertilization. Parameters such as progressive forward motility, VSL, VCL, ALH and LIN were associated with the fertility of the bull (Farrell et al., 1996; Perumal et al., 2011). The VSL is the determination of average path velocity of spermatozoa head along a straight line from its starting position to last position measured. The VCL is the average path velocity of the spermatozoa head along its actual trajectory. The percentage of LIN is the ratio between VSL and VCL. The ALH is the average value of the extreme side-to-side movement of the spermatozoa head in each beat cycle. A very high ALH and VCL in the spermatozoa suggested the higher bending of the mid piece and having a higher ALH. This gives importance the hyperactivation of the spermatozoa.

The high energy state of the germ cells is the hyperactivation, which is essential for sperm penetrating through the cervical mucus and thus fusing with the oocytes (Aitken et al., 1985). Spermatozoa velocity and motility parameters indicate indirectly their mitochondrial membrane potential. In cattle species, some specific motion and velocity parameters have been reported to be correlated to fertility (Budworth et al., 1988; Farrell et al., 1996). However, the threshold levels for velocity and mobility parameters have not yet been standardized to understand a general consensus purpose . Furthermore, the CASA parameter, linearity or linear motility is significantly higher suggests that the sperm cells has higher fertilization potential rate as compared to the total as well as forward progressive motility (Cremades et al., 2005) and ejaculates contains such sperm has higher fertility percentage and pregnancy rates after artificial breeding (Farrell et al.,1998).

Recent findings suggested that determination of motile spermatozoa in a ejaculate may not be recognized as a reliable and useful index in semen assessment and conservation. The objective and subjective estimation of other sperm velocity and motion parameters obtained from observations of individual sperm cells assessed by CASA have been seen to be more efficient in diagnosing the fertility potential of ejaculates (Mortimer, 1994). All these CASA parameters are probably essential for the progression and forward movement of sperm into estrus cervical mucus and the passage and/or penetration of zona pellucida and successful fertilization (Verstegen et al., 2002). Fertilization rates of oocytes in in vitro have been showed to associated positively with sperm velocity and motility (Donnely et al., 1998).

In cattle species, sperm velocity parameter is highly correlated with the $59 \mathrm{~d}$ non-return rate (Farrell et al., 1998). VCL and $\mathrm{BCF}$ were significantly higher indicates the spermatozoa have higher percentage that penetrated in penetration assay than the sperms failed to penetrate successfully in experiment related with human beings (Fetterlof \& Rogers, 1990). The computerized sophisticated technique is not only prognoses the semen fertility and but also can be used as a tool to study the effects of different in-vitro protocols on sperm velocity and motility as well as the sperm hyperactivation phenomenon (Farrell et al., 1993) and similar observation was found in the current study.

Based on the current study, it was concluded that unilateral cryptorchidism causes subfertility/infertility in males due to significant alterations in the seminal and scrotal \& testicular parameters of mithun. Results revealed from the study that most of the important sperm velocity and motility parameters of computer assisted sperm analyser were significantly lower in ejaculates of cryptorchid mithun bulls in comparison to the ejaculates of normal intact mithun bulls. Due to the genetic hereditary nature, cryptorchid or monorchid diagnosed bulls never be used for breeding purposes either natural or AI program.

\section{Acknowledgements}

This research work was supported by a grant from the Department of Biotechnology, Government of India, New Delhi for the project entitled "Evaluation of melatonin as fertility marker in Mithun (Bos frontalis) bulls: Effect on circadian rhythm and seasonal variation in semen quality parameters".

\section{Conflict of interest}

Authors would hereby like to declare that there is no conflict of interests that could possibly arise.

\section{References}

Aitken RJ, Sutton M, Warner P, Richardson DW (1985) Relationship between the movement characteristics of human spermatozoa and their ability to penetrate cervical mucus and zona free hamster oocytes. Journal of Reproduction and Fertility 73: 441-449. DOI: 10.1530/jrf.0.0730441

Amann RP, Veeramachaneni DNR (2007) Cryptorchidism in common eutherian mammals. Reproduction 133: 541 - 561. DOI: 10.1530/REP-06-0272

Anil Kumar R, Sundararaman MN, Patel DV, Iyue M, Kasiraj $R$ (2011) Cryopreservation of semen as a venture for conservation of wild and endangered Toda buffalo germplasm. Buffalo Bulletin $30: 210-218$.

Blasco L (1984) Clinical tests of sperm fertilizing ability. Fertility and Sterility 41: 177-192. DOI: http://dx.doi.org/10.1016/S0015-0282(16)47976-8

Broekhuijse MLWJ, Šoštarić E, Feitsma H, Gadella BM (2012) Application of computer-assisted semen analysis to explain variations in pig fertility. Journal of Animal Science 90 : 779-789. doi: 10.2527/jas.2011-4311. 
Budworth PR, Amann RP, Hammerstedt RH (1988) A microcomputer-photographic method for evaluation of motility and velocity of bull sperm. Journal of Dairy Science 70: 19271936. DOI: 10.3168/jds.S0022-0302(87)80233-3

Cremades T, Roca J, Rodriguez-Martinez H, Abaigar T, Vazquez JM, Martinez EA (2005) Kinematic changes during the cryopreservation of boar spermatozoa. Journal of Andrology 26 : 610- 618. DOI: 10.2164/jandrol.05028

Domosławska A, Zduńczyk S, Niżański W, Janowski T(2013) Assessment of semen quality in infertile dogs using computerassisted sperm analysis by the Hamilton-Thorne Semen Analyser. Bulletin of the Veterinary Institute in Pulawy 57: 429-432. DOI: 10.2478/bvip-2013-0074

Donnely ED, Lewis SEM, McNally JA, Thompson W (1998) In vivo fertilization and pregnancy rates: the influence of sperm motility and morphology on IVF outcome. Fertility and Sterility 70: 304-314. DOI: http://dx.doi.org/10.1016/S00150282(98)00146-0

Farrell PB, Foote RH, Simkin ME, Clegg ED, Wall RJ (1993) Relationship of semen quality, number of sperm inseminated, and fertility in rabbits. Journal of Andrology 14: 464-471. DOI: 10.1002/j.1939-4640.1993.tb03264.x

Farrell PB, Presicce GA, Brocektt CC, Foote RH (1998) Quantification of bull sperm characteristics measured by computer-assisted sperm analysis (CASA) and their relationship to fertility. Theriogenology 49: 871-879. DOI: 10.1016/S0093-691X(98)00036-3

Farrell PB, Foote RH, McArdle MM, Trouern-Trend VL, Tardif AL (1996) Media and dilution procedures tested to minimize handling effects on human, rabbit, and bull sperm for computer-assisted sperm analysis (CASA). Journal of Andrology 17 : 293-300. DOI: 10.1002/j.19394640.1996.tb01785.x

Fetterlof PM, Rogers BJ (1990) Prediction of human sperm penetrating ability using computerized motion parameters. Molecular Reproduction and Development 27: 326-331. DOI: 10.1002/mrd.1080270406

Froman DP, Feltmann AJ, Rhoads ML, Kirby JD (1999) Sperm mobility: a primary determinant of fertility in the domestic fowl. Biology of Reproduction 61: 400-405. DOI: 10.1095/biolreprod61.2.400

Froman DP, Feltmann AJ (1998) Sperm mobility: a quantitative trait of the domestic fowl (Gallus domesticus). Biology of Reproduction 58: 379-384. DOI: 10.1095/biolreprod58.2.379

Gopalkrishnan K, Padwal V, D’Souza S, Shah R(1995) Severe asthenozoospermia: a structural and functional study.
International Journal of Andrology 18: 67-74. DOI: 10.1111/j.1365-2605.1995.tb00388.x

Igbokwe IO, Abba Y, Geidam SU, Igbokwe NA(2013) Sperm output from unilateral cryptorchid Sahel goats. Comparative Clinical Pathology DOI 10.1007/s00580-013-1695-7

Iguer-Ouada M, Verstegen J(2001) Evaluation of the Hamilton Thorn computer-based automated system for dog semen analysis. Theriogenology 55: 733-749. DOI: http://dx.doi.org/10.1016/S0093-691X(01)00440-X

Kaki T, Sofikitis N (1999) Effect of unilateral cryptorchidism on contralateral epididymal sperm quality, quantity and fertilizing capacity. Yonago Acta Medica 42:79-86.

Kawakami E, Tsutsui T, Saito S, Kakimoto T, Ogasa A(1995) Changes in peripheral plasma luteinizing hormone and testosterone concentration and semen quality in normal and cryptorchid dogs during sexual maturation. Laboratory Animal Science 45:258-263.

Koonjaenak S, Chanatinart V, Aiumlamai S, Pinyopumimintr $\mathrm{T}$, Rodriguez-Martinez H(2007) Seasonal variation in semen quality of swamp buffalo bulls (Bubalus bubalis) in Thailand. Asian Journal of Andrology 9 : 92-101. DOI: 10.1111/j.17457262.2007.00230.x

Kozdrowski R, Dubiel A, Bielas W, Dzięcioł M (2007) Two protocols of cryopreservation of goat semen with the use of computer-assisted semen analysis system. Acta Veterinaria Brno 76: 601-604. DOI: http://dx.doi.org/10.2754/avb200776040601

Kumar D, Joshi A, Naqvi SMK (2010) Comparative semen evaluation of Malpura and Bharat merino rams by computeraided sperm analysis technique under semi-arid tropical environment. International Journal of Animal and Veterinary Advance $2: 26-30$.

Marcus S, Shore LS, Perl S, Bar-el M, Shemesh M (1997) Infertility in a cryptorchid bull: a case report. Theriogenology 48:341 - 352. DOI: http://dx.doi.org/10.1016/S0093$691 X(97) 00245-8$

Mieusset R, Bujan L, Massat G, Mansat A, Pontonnier F (1995) Clinical and biological characteristics of infertile men with a history of cryptorchidism. Human Reproduction 10: 613-619.

Mortimer D, Shu MA, Tan R (1986) Standardization and quality control of sperm concentration and sperm motility counts in semen analysis. Human Reproduction 1: 299-303.

Mortimer D (1994) Practical Laboratory Andrology. New York: Oxford University Press. 
Mortimer ST (1997) A critical review of the physiological importance and analysis of sperm movement in mammals. Human Reproduction Update3: 403 - 439 DOI: 10.1093/humupd/3.5.403

Palmer C, Amundson S, Brito L, Waldner C, Barth A (2004) Use of oxytocin and cloprostenol to facilitate semen collection by electro-ejaculation or transrectal massage in bulls. Animal Reproduction Science 80: 213-223. DOI: 10.1016/j.anireprosci.2003.07.003

Patkowski D, Jelen M, Crerni KJ (1992) The normal course of cryptorchidism in rat and efficacy of orchidopexy or orchidectomy in its treatment before and after puberty. Journal of Pediatric Surgery 27:870-873.

Perumal P, Selvaraju S, Selvakumar S, Barik AK, Mohanty DN, Das S, Das RK, Mishra PC (2011) Effect of pre-freeze addition of cysteine hydrochloride and reduced glutathione in semen of crossbred Jersey bulls on sperm parameters and conception rates. Reproduction in Domestic Animal 46 : 636641. DOI: 10.1111/j.1439-0531.2010.01719.x.

Perumal P (2008) Cryopreservation of bovine semen with some additives for augmenting fertility. M.V.Sc. Thesis submitted to Orissa University of Agriculture and Technology, Bhubaneswar, Orissa, India.

Pinart E, Sancho S, Briz MD, Bonet S, Garcia N(1999) Characterization of the semen quality of post puberal boars with spontaneous unilateral abdominal cryptorchidism on the right side. Animal Reproduction Science 55: 269-278. DOI: http://dx.doi.org/10.1016/S0378-4320(99)00022-6

Raś A, Rapacz A, Raś-Noryńska M, Janowski TE (2010) Clinical, hormonal and ultrasonograph approaches to diagnosing cryptorchidism in horses. Polish Journal of Veterinary Sciences $13: 473-477$.

Sarsaifi K, Rosnina Y, Ariff MO, Wahid H, Hani H, Yimer N, Vejayan J, Win Naing S, Abas MO (2013) Effect of semen collection methods on the quality of pre- and post-thawed Bali cattle (Bos javanicus) spermatozoa. Reproduction in Domestic Animal 48 : 1006-1012. DOI: 10.1111/rda.12206

Smith KC, Brown PJ, Barr FJ, Parkinson TJ(2012) Cryptorchidism in Sheep: A Clinical and Abattoir Survey in the United Kingdom. Open Journal of Veterinary Medicine 2: 281-284. DOI: http://dx.doi.org/10.4236/ojvm.2012.24044.

Tellalogus S, Kadioglu A, Kilicaslan I(1994) Cryptorchidism: is orchidopexy always preventive treatment for infertility? Acta Chir Hungatica 34:195-201.

Verstegen J, Iguer-Ouada M, Onclin M(2002) Computer assisted semen analyzers in andrology research and veterinary practice. Theriogenology 57: 149-179. DOI: http://dx.doi.org/10.1016/S0093-691X(01)00664-1

Yeung CH, Cooper TG, Oberpenning F, Schulze H, Nieschlag $\mathrm{E}(1993)$ Changes in movement characteristics of human spermatozoa along the length of the epididymis. Biology of Reproduction 49: 274-280. DOI: 10.1095/biolreprod49.2.274. 